\title{
Kangaroo Mother Care: A Simple Method to Care for Low- Birth-Weight Infants in Developing Countries
}

\author{
Akhtar $\mathrm{K}^{1}$, Haque $\mathrm{M}^{2}$, Khatoon $\mathrm{S}^{3}$
}

\begin{abstract}
Kangaroo Mother Care (KMC) is an effective way to meet baby's needs for warmth, breastfeeding, protection from infection, stimulation, safety and love. Mother acts as an incubator as kangaroo and put low birth infant vertically in between the chest for warming. The term kangaroo care is derived from practical similarities to marsupial care-giving. The premature infant is kept warm in the maternal pouch and is close to the breasts for unlimited feeding. It provides an alternative to incubator care, without separation from the mother. The importance of KMC in low- and middle-income countries has been highlighted as a contributing factor to the achievement of the Millennium Development Goal 4 that targets a reduction by two-thirds of under-five mortality rates from 1990 to 2015. This programme is mediated by humoral, autonomic and somatic behaviours, expressed ultimately as innate competency in breastfeeding behaviours. It is simple, acceptable to mothers and can be continued at home. [J Shaheed Suhrawardy Med Coll, 2013;5(1):49-54]
\end{abstract}

Key words: Kangaroo Mother Care, low birth weight, skin to skin contact

Recived: November 2012; Revised : March 2013; Accepted: may 2013

\subsection{Introduction}

Low birth weight, defined as weight at birth of less than $2500 \mathrm{~g}$ irrespective of gestational age, has an adverse effect on child survival and development ${ }^{1}$. World-wide Low birth weight $(\mathrm{LBW})$ is a major problem ${ }^{2,3,4}$ with an average incidence of $18.0 \%$ globally and $33.0 \%$ in developing countries $^{2}$. It is a major contributor to neonatal and infant mortality and morbidity with about $30.0 \%$ of neonatal mortality related to it in developing countries. LBW approximately doubles the neonatal mortality rate in a periurban setting in Bangladesh ${ }^{2}$. Thus the care of such infants becomes a burden for health and social systems everywhere. Traditionally, these infants born in hospital are kept in incubators or radiant warmers ${ }^{5,6}$ or warm room with open cots. Neonatal intensive care of LBW babies is difficult in developing countries due to high cost, difficulty in maintenance and repairs of equipments, intermittent power supply, inadequate cleaning of instruments and shortage of skilled staff. For sharing the incubator, risk of infection to infant is very high. The mothers are used as "incubators" they are the main source of food and stimulation for LBW infants. It can be practised in any situation or context, as because no special equipment or technology like cots, heaters or incubators is needed 5 .

\subsection{History of KMC}

KMC was first suggested in 1978 by Dr Edgar Rey in Bogotá, Colombia develop a technologically simple method later named 'Kangaroo mother care' (KMC) $)^{6,7,8}$. KMC method was defined as 'Early, continuous and prolonged mother-infant skin-to-skin contact, with (ideally) exclusive breastfeeding ${ }^{7}$.

\subsection{Significance of KMC}

There is evidence that KMC helps with thermal regulation $^{3,6}$, reduces stress, protects against infection, enhances breastfeeding, lactation, and bonding, improves infant growth ${ }^{3,9}$ and contributes to improved neonatal survival. At the time of the implementation of KMC- in Ghana's under-five mortality rate (U5MR) \& infant mortality rate (IMR) was very high near about 115 and 73 per 1,000 live births respectively ${ }^{3}$. Although the U5MR and the IMR decreased over the previous decade, the neonatal mortality rate (NMR) remained static at 43 deaths

1. Dr. Khursheda Akhtar, Lecturer, Department of Community Medicine, Shaheed Suhrawardy Medical College, Dhaka.

2. Prof. Dr. Musarrat Haque, Professor \& Head, Department of Community Medicine, Shaheed Suhrawardy Medical College, Dhaka.

3. Prof. Dr. Soofia Khatoon, Professor \& Head, Department of Paediatrics, Shaheed Suhrawardy Medical College, Dhaka

\section{Correspondence}

Dr. Khursheda Akhtar, Lecturer, Department of Community Medicine, Shaheed Suhrawardy Medical College, Sher-E-Bangal Nagar, Dhaka, Bangladesh; Email: mukta1972@yahoo.com; Cell: +8801714712174

Conflict of Interest: Not declared

Financial support: None

Contribution to Authors: Dr. K. Akhtar has the concptas well as the write up of the article. Prof. Dr. M. Haque \& Prof. Dr. S. Khatoon have reviewed the article 
per 1,000 live births ${ }^{3}$. Estimates of the LBW rate ranged from $9.1 \%$ to $16^{\circ} \%^{3}$. These small infants accounted for the majority of newborn deaths. KMC is therefore identified as one of the solutions to the problems associated with high neonatal mortality rates in Ghana ${ }^{3}$.

\subsection{Components of KMC}

Skin-to-skin contact, frequent and exclusive or nearly exclusive breast feeding, early discharge from hospital regardless of weight or gestational age are the components of $\mathrm{KMC}$.

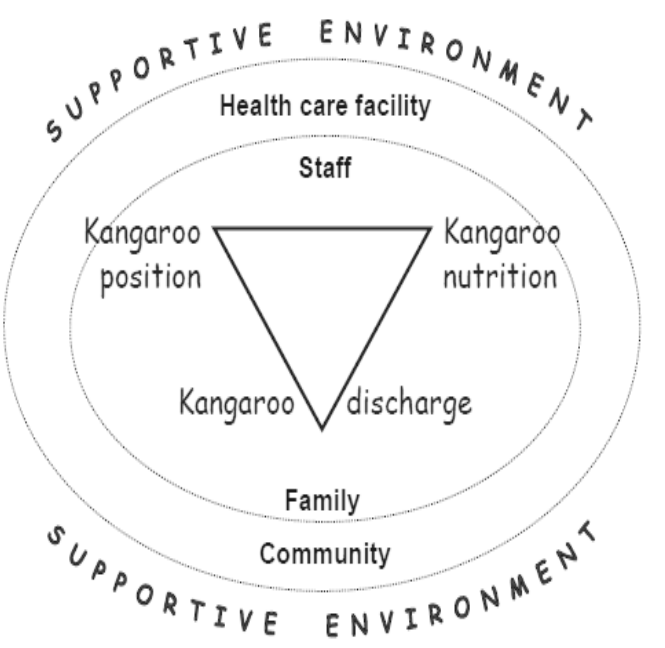

Figure 1: The Components of Kangaroo mother Care ${ }^{10}$

\subsection{Kangaroo Position (skin to skin contact)}

The kangaroo position consists of skin-to-skin contact (SSC) between the mother and the infant in a strictly vertical position. The infant will be placed between the mother's breasts and under her clothes. SSC should be started as early as possible after birth. It can be two types depending upon the duration which are continuous or intermittent ${ }^{8,11}$.

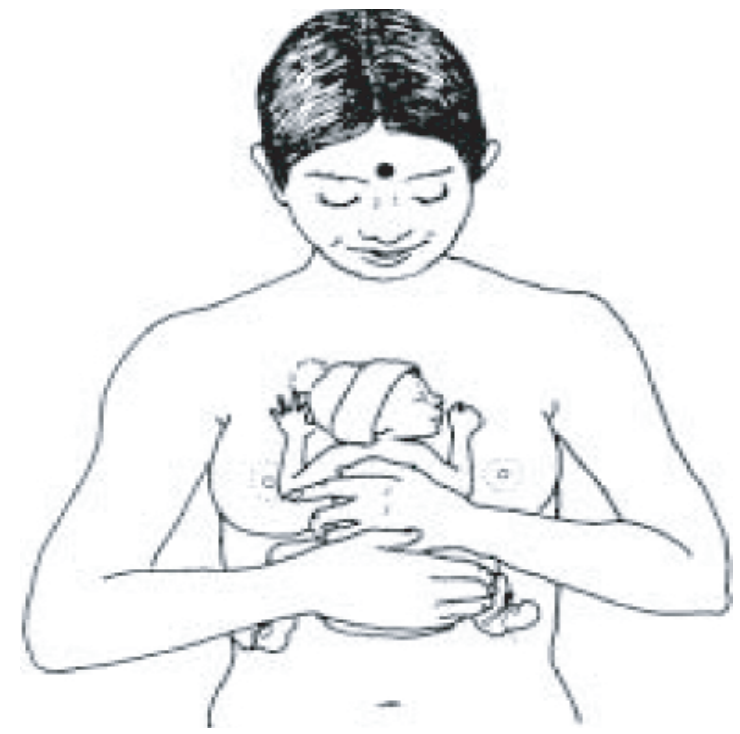

Figure II: Kangaroo positioning ${ }^{8,11}$

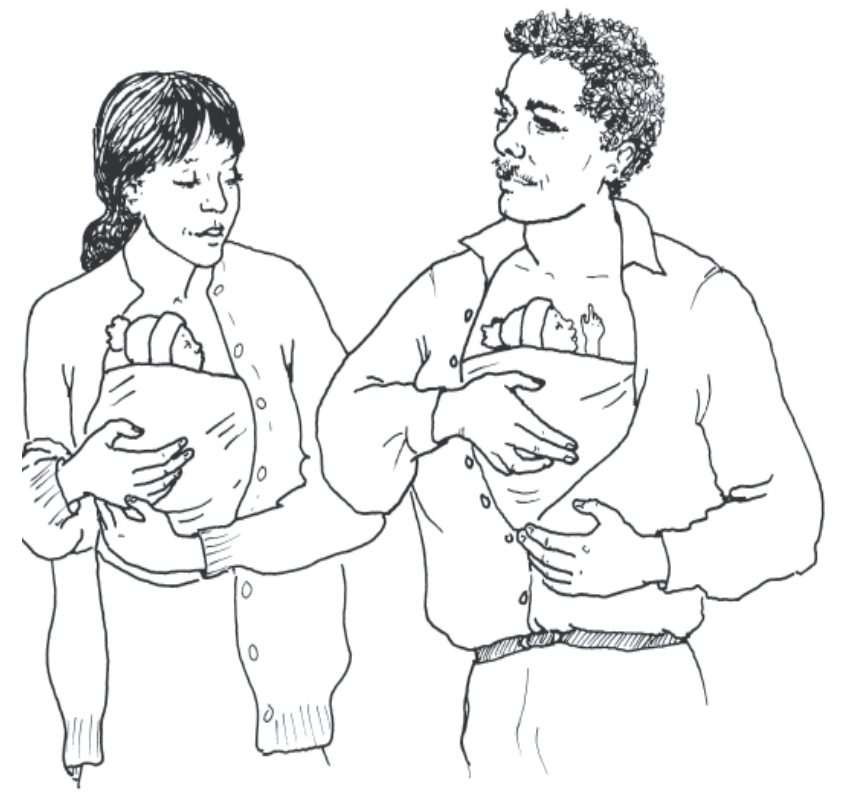

Figure III: Holding the baby close to the chest ${ }^{12}$

\subsection{Kangaroo Nutrition}

Kangaroo nutrition is the delivery of nutrition to "kangarooed" infants as soon as oral feeding is possible. It is based on exclusive breastfeeding by direct sucking, whenever possible. Goal is to provide exclusive or nearly exclusive breastfeeding ${ }^{8,11}$.

\subsection{Kangaroo Discharge and Follow Up}

Early home discharge in the kangaroo position from the neonatal unit is one of the original components of the KMC intervention ${ }^{8,11}$.

\subsection{Benefits of KMC}

$\mathrm{KMC}$ is compared with Conventional method of care (CMC). KMC reduces mortality, severe infection and sepsis, nosocomial infections, hypothermia, severe illness, lower respiratory tract disease and length of hospital stay. $\mathrm{KMC}$ resultes in improved weight and length, head circumference, breastfeeding, mother-infant bonding and maternal satisfaction with the method of care, as compared with conventional methods ${ }^{13}$.

\subsection{Effect on breastfeeding}

Rao et $\mathrm{al}^{9}$ mentioned that the rate of exclusive breastfeeding (98\% vs. 76\%) was found higher in KMC group. The number of mothers exclusively breastfeeding their babies at 6 week follow-up was double in the KMC group than in the control group (12/14 vs. 6/14) ${ }^{8}$. Women in the Community Kangaroo Mother Care (CKMC) group began to breastfeed earlier than control group. KMC mother breastfed their child 3.4 hours sooner after birth $(\mathrm{P}<.001)$. Few mother breastfed immediately after birth and $52.4 \%$ of CKMC mothers breastfed within 1 hour of birth compared with $41.4 \%$ in the control group $(\mathrm{P}<.001)^{4}$. 
Table 1 : Different studies on KMC

\begin{tabular}{|c|c|c|c|c|c|}
\hline Study/ year & Country & Sample & Infants age & $\begin{array}{l}\text { Infant use } \\
\text { KMC }\end{array}$ & $\begin{array}{l}\text { Infant not } \\
\text { use KMC }\end{array}$ \\
\hline Whitelaw et $\mathrm{al}^{15}$ & England & 71 preterm infants with $\mathrm{BW}>1500 \mathrm{gm}$ & $6 \mathrm{wks}$ & 55 & 28 \\
\hline \multirow[t]{3}{*}{ Charpak et al ${ }^{16}$} & Colombia & 1,084 infants with $\mathrm{BW}>2,000 \mathrm{~g}$ & 1 month & 93 & 78 \\
\hline & & & 6month & 70 & 37 \\
\hline & & & 1 year & 41 & 23 \\
\hline \multirow[t]{3}{*}{ Lima et $\mathrm{al}^{17}$} & Brazil & 114 preterm infants, with mean GA of & HD & 88 & \\
\hline & & 33.4 weeks and mean BW of $1,476 \mathrm{~g}$ & 1 month & 87 & \\
\hline & & & 3 months & 63 & \\
\hline Ramanathan et al ${ }^{18}$ & India & 28 preterm infants with $\mathrm{BW}>1,500 \mathrm{~g}$ & $6 \mathrm{wks}$ & 85.7 & 42.8 \\
\hline \multirow[t]{3}{*}{ Charpak et al ${ }^{19}$} & Colombia & 679 preterm infants, with mean GA of & 1 month & 98 & \\
\hline & & 32 to 37 weeks and mean BW of $1,685 \mathrm{~g}$ & 3 months & 81.7 & \\
\hline & & & 6 months & 51.6 & \\
\hline
\end{tabular}

*KMC: Kangaroo mother care; BW: birth weight; GA: gestational age, HD=Hospital discharge

\subsection{Reducing infant morbidity and mortality}

A significantly higher number of babies in the Conventional Method of Care (CMC) group suffered from hypothermia, hypoglycemia, and sepsis ${ }^{9}$ with a significant reduction in respiratory rate, increasing rectal temperature, oxygen saturation seen after 1 hour of kangaroo care compared to the conventional care ${ }^{20}$. In a Meta-analysis it was showed that KMC in the first week of life had a significant reduction in neonatal mortality [RR $0.49,95 \%$ CI 0.29-0.82] compared with standard care. There was also a significant benefit of mortality (RR $0.68,95 \%$ CI 0.58 $0.79)$ \& serious morbidity for babies $<2000 \mathrm{~g}$ (RR 0.34 , 95\% CI 0.17-0.65). The Cochrane review ${ }^{13}$ included seven trials that assessed mortality at discharge or at 40-41 weeks. These trials reported a statistically significant reduction $3.4 \%$ in the risk of mortality among $\mathrm{KMC}$ infants, compared with $5.7 \%$ for babies receiving traditional care. In five studies involving 1520 infants suggested that there was a major reduction of neonatal morbidity (RR $0.34,95 \%$ CI $0.17-0.65$ ). Morbidity was defined as severe infection such as sepsis, necrotizing entercolitis and severe pneumonia ${ }^{21,22}$. The analysis of randomized trials showed that it consists in a protection factor to breastfeeding at discharge (relative risk $0.41,95 \%$ confidence interval 0.25 to 0.68 ). The method was always associated with the following reduced risks of nosocomial infection (RR 0.49 , 95\% CI 0.25 to 0.93 ), severe illness (RR $0.30 ; 95 \%$ CI 0.14 to 0.67 ), lower respiratory tract disease at 6 months (RR $0.37,95 \%$ CI 0.15 to 0.89$)^{1,14}$. Experiment carried out in developing countries showed that $\mathrm{KMC}$ was safe in terms of mortality, morbidity and avoid hospital readmissions ${ }^{14}$.

\subsection{Physiological Variables of KMC Infants}

Physiological parameter of babies in the KMC group have significant lesser episodes of hypothermia, high oxygen saturation \& reduction in respiratory rate as compared to CMC group ${ }^{5,20}$. Hypoglycaemia was $4 \%$ in $\mathrm{KMC}$ and $36 \%$ in CMC ( $<<0.001)^{9}$. Stability can be measured by using a composite cardio-respiratory stabilization score (SCRIP). SCRIP consists of heart rate, oxygen saturation, and respiratory rate. In SCRIP it was shown that 35 infants were analysed in comparable groups in which SSC compared to incubator babies exceeded the pre-determined parameters $(p<0.001)$. Stabilization scores were 77.11 for SSC versus 74.23 for incubator. All SSC subjects were stable in the sixth hour, compared to $6 / 13$ incubator infants; however 8/13 incubator subjects experienced hypothermia $^{23}$. CKMC mothers delayed newborn bathing ${ }^{24}$.

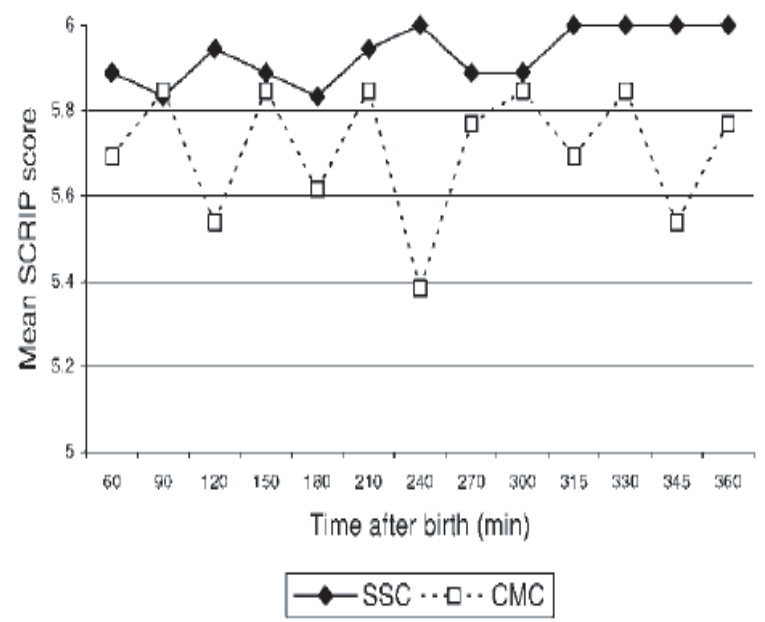

Figure IV: Average SCRIP scores through study population ${ }^{23}$

\subsection{KMC and Weight Gain}

KMC babies achieve better growth the KMC babies had better average weight gain per day was (KMC $23.99 \mathrm{gm}$ vs. CMC $5.58 \mathrm{gm} ; \mathrm{p}<0.001)^{9}$. The weekly increment in head circumference, chest circumference gain, mid-arm circumference gain and foot length gain was statistically significant $(\mathrm{P}<0.001)^{9}$. KMC babies gained more weight than those in the control group ${ }^{18,25}$. 


\subsection{Psychological aspect and KMC}

Mothers prefer skin-to-skin contact to conventional care and report an increased confidence, self-esteem and feeling of fulfilment, They describe a sense of empowerment, confidence and a feeling that they can do something positive for their preterm infants in different settings and cultures $^{12}$.

\subsection{Duration of Hospital Stay}

Randomized control trial study to neonates in the $\mathrm{KMC}$ group demonstrated that $\mathrm{KMC}$ infants discharged from hospital earlier than control group ${ }^{6,18}$. Infants who received conventional care stayed longer in the hospital than the $\mathrm{KMC}$ infants $^{20}$ and reduce readmission ${ }^{14}$.

\subsection{Cost-effectiveness of KMC}

$\mathrm{KMC}$ is a cost-effective alternative to incubator care for LBW newborns in low-resource settings. The preliminary findings demonstrate the feasibility, acceptability, and effectiveness of KMC in rural Matlab ${ }^{8,26}$ and Lamb project $^{27}$. The burden on health systems imposed by care of preterm infants in high-income countries is considerable and well recognized. Indeed it is estimated that the cost of care for a single preterm birth in the USA ${ }^{21}$ is US\$ 51600. This challenge still largely remains invisible in low-income countries however it is actually of greater magnitude as preterm birth rates are higher and resources are low with understaffed hospitals, poorly equipped or non-existent neonatal care units which ultimately result in higher neonatal mortality rates ${ }^{21}$. Lower capital investment and recurrent costs is yet another advantage of KMC and could bring about some savings to hospitals and health care systems in low-income countries ${ }^{12}$.

\subsection{Criteria for Eligibility of KMC}

\subsection{Baby}

All stable LBW babies are eligible for KMC. Short KMC sessions can be initiated during recovery with ongoing medical treatment like IV fluids, oxygen therapy. KMC can be provided while the baby is being fed via oro-gastric tube or on oxygen therapy.

\subsection{Mother}

All mothers can provide KMC irrespective of age, parity, education, culture and religion. The following points must be taken into consideration when counseling on KMC like willingness, general health and nutrition, hygiene, supportive family and community.

\subsection{Monitoring}

Babies receiving $\mathrm{KMC}$ should be monitored carefully especially during the initial stages. Nursing staff should ensure that baby's

- Neck is not too flexed or too extended,

- Breathing is normal, and

- Feet and hands are warm

Mother should be involved in observing the baby during
$\mathrm{KMC}$, so that mother herself can continue monitoring at home $\mathrm{e}^{8,11}$.

\subsection{Duration of KMC}

Skin-to-skin contact should start gradually in the nursery, with a smooth transition from conventional care to continuous KMC. Sessions that last less than one hour should be avoided because frequent handling may be stressful for the baby. The length of skin-to-skin contacts should be gradually increased up to 24 hours/day. When the baby does not require intensive care, baby should be transferred to the post-natal ward where KMC should be continued. When the mother and baby are comfortable, $\mathrm{KMC}$ is continued for as long as possible, even in the hospital as well as at home. Often this is desirable until the baby's gestation reaches term or the weight is around 2500 $\mathrm{gm}^{8,11}$.

\subsection{KMC during Sleep and Resting of Mother}

The mother can sleep with baby in kangaroo position in reclined or semi recumbent position about 15 degrees from horizontal. Preferred positions for KMC were semi-sitting followed by lying-down ${ }^{28}$. The mothers are encouraged to keep the baby in $\mathrm{KMC}$ as long as possible during the day and night with a minimum period of one to two hours at a time ${ }^{11}$. When the babies are receiving intravenous fluids, mother provided kangaroo care seated in a comfortable chair placed close to the baby's cradle. Once the baby is on full feeds, mother may provide kangaroo care on the reclining cot in the semi upright position with the help of pillows. In KMC ward "KMC chart" can be given to keep a record of the duration of kangaroo care provided. When mother is not available, other family member such as grandmother, father or other relative can provide KMC. In response to these multiple challenges, a local programme for Kangaroo Father Care will be added, which will be also beneficial. Under such circumstances, it is evident that a holistic approach based on the concept of Kangaroo Family Care is necessary for optimal KMC practice ${ }^{11}$.

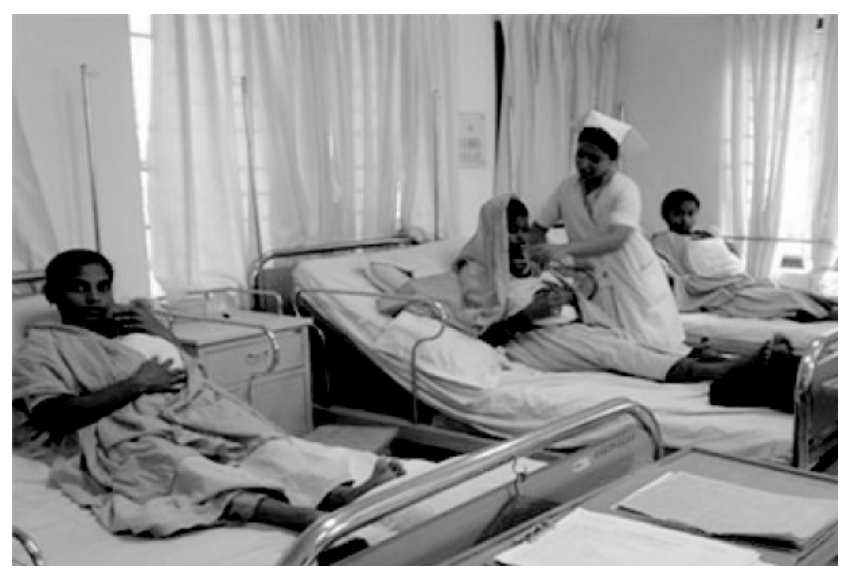

Figure V: The Kangaroo Mother Care ward at icddr,b's Matlab Health Research Centre 


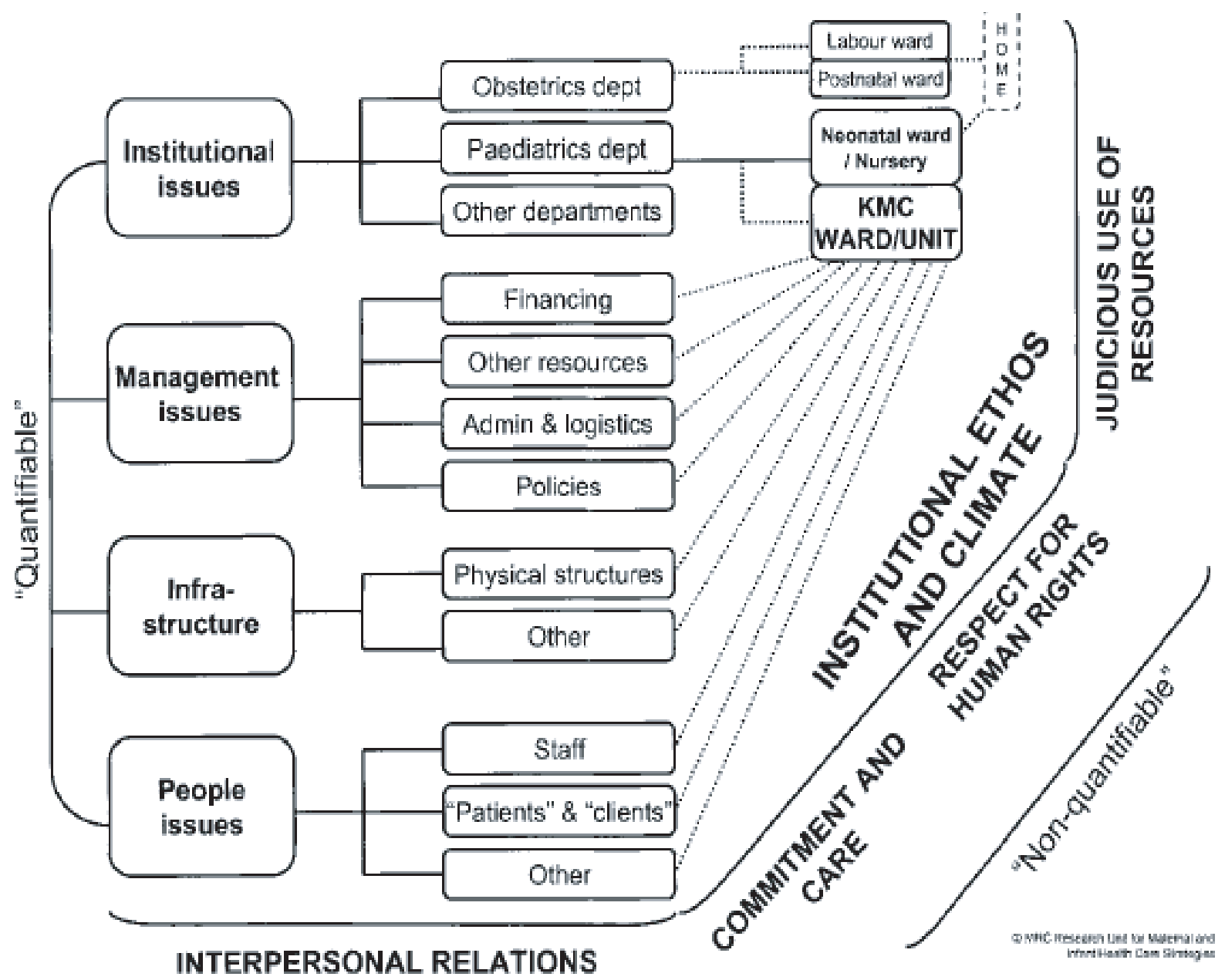

Figure VI: Main issues in the establishment of $\mathrm{KMC}^{29}$

\subsection{Post-discharge follow-up}

Close follow up is a fundamental pre-requisite of $\mathrm{KMC}$ practice. Baby is followed once or twice a week till 37-40 weeks of gestation or till the baby reaches $2.5-3 \mathrm{~kg}$ of weight $^{8.11}$. Thereafter, a follow up once in 2-4 weeks may be enough till 3 months of post conception age. Later the baby should be seen at an interval of 1-2 months during first year of life $\mathrm{e}^{8,11}$.

\subsection{Setting of KMC in a hospital}

It is essential to (sufficiently) strengthen KMC services in healthcare facilities before expanding the programme. Establishment of KMC will be first start with institutional issues, management issues, infrastructure and people issues $^{29}$. Through Department of Obstetrics, Paediatrics and other departments and with all other facilities like logistics, finance, administration, staff, policies, labour ward, and postnatal ward KMC ward will be established in a hospital. KMC was successfully adapted in Bangladesh as pilot study ${ }^{4,30,31}$. It is established that community-based kangaroo mother care reduces the overall neonatal mortality rate by $27.5 \%$, infant mortality rate by $25^{\circ} \%$, and low birth weight neonatal mortality rate by $30^{\circ} \%{ }^{4}$.

\subsection{Conclusion}

There are controversies and challenges with the effectiveness of Kangaroo Mother Care (KMC) in reducing infant mortality. In low-income countries, most births occur at home and neonatal intensive care is virtually unavailable, leading to high incidence of LBW and NMR is high. In these circumstances, initiation of CKMC promptly after birth could prove to be an effective means of timely thermal stabilization and early initiation and establishment of breastfeeding and thus potentially reduce the neonatal mortality rate (NMR) and IMR.

\section{References}

1. Conde-Agudelo A, Belizán JM. Kangaroo Mother Care to Reduce Morbidity and Mortality in Low birth weight Infants (Review). The Cochrane Collaboration. http://www.thecochrane library.com

2. Yasmin S, Osrin D, Paul E, Costello A. Neonatal Mortality of Lowbirth-weight Infants in Bangladesh. Bull WHO, 2001;79: 608-14

3. Bergh AM, Manu R, Davy K, Rooyen EV, Asare GQ, Williams JKA, et al. Translating Research Findings into Practice - The Implementation of Kangaroo Mother Care in Ghana. Implementation Science 2012; 7:75-80 4. Sloan NL, Ahmed S, Mitra SN, Choudhury N, Chowdhury M, Rob U, et al. Community-Based Kangaroo Mother Care to Prevent Neonatal and Infant Mortality: A Randomized, Controlled Cluster Trial. Pediatrics 
2008;121(5):1047-59

5. Kadam S, Binoy S, Kanbur W, Mondkar JA, Fernandez A. Feasibility of Kangaroo Mother Care in Mumbai. Indian J Pediatr 2005;72(1):35-8

6. Gathwala G, Singh B, Balhara B. KMC Facilitates Mother Baby Attachment in Low Birth Infants. Indian J Pediatr 2008;75:43-7

7. Nyqvist KH, Anderson GC, Bergman N, Cattaneo A, Charpak N, Davanzo R, et al. Towards Universal Kangaroo Mother Care: Recommendations and Report from the First European Conference and Seventh International Workshop on Kangaroo Mother Care. Acta Pædiatrica 2010;99: 820-26

8. Thukral A, Chawla D, Agarwal R, Deorari AK, Paul VK. Kangaroo Mother Care-an Alternative to Conventional Care. Indian J Pediatr 2008;75: 497-503

9. Rao S, Udani R, Nanavati R. Kangaroo Mother Care for Low Birth Weight Infants:A Randomized Controlled Trial: Indian Pediatrics. 2008; 45:17-23

10. Bergh AM, Davy K, Otai CD, Nalongo AK, Sengendo NH, Aliganyira P. Evaluation of Kangaroo Mother Care Services in UGANDA. April 2012 11. Website of KMC India Network. 2012; Guidelines for parents and health providers are available online at www.kmcindia.org

12. World Health Organization. Kangaroo Mother Care: a practical guide. Department of Reproductive Health and Research, WHO, Geneva.2003

13. Kangaroo Mother Care, Implementation Guide, Save the Children, the White Ribbon Alliance for Safe Motherhood. USAID for American People, Maternal and Child Health Integrated Program

14. Venancio SI, Almeida Hd. Kangaroo Mother Care: Scientific Evidences and Impact on Breastfeeding. Jornal de Pediatria 2004;80(5):21-23

15. Whitelaw A, Heisterkamp G, Sleath K, Acolet D, Richards M. SkinTo-Skin Contact for Very Low Birth Weight Infants and Their Mothers. Arch Dis Child. 1988;63:1377-81

16. Charpak N, Ruiz-Pelaez JG, Charpak Y. Rey Martinez. Kangaroo Mother Care Program: An Alternative Way of Caring for Low Birth Weight Infants? One Year Mortality in Two Cohort Studies. Pediatrics. 1994;94:804-10

17. Lima G, Quintero-Romero S, Cattaneo A. Feasibility, Acceptability and Cost of Kangaroo Mother Care in Recife, Brazil. Ann Trop Paediatr. 2000;20:22-6
18. Ramanathan K, Paul VK, Deorari AK, Taneja U, George G. Kangaroo Mother Care in very low birth weight infants. Indian J Pediatr. 2001;68:1019-23

19. Charpak N, Ruiz-Pelaez JG, Figueroa de Calume Z, Chapark Y. A Randomized, Controlled Trial of Kangaroo Mother Care: Results of Follow-Up at 1 Year of Corrected Age. Pediatrics. 2001;108:1072-9

20. Ali SM, Sharma J, Sharma R, Alam S. Kangaroo Mother Care as Compared to Conventional Care for Low Birth Weight Babies. Dicle Med J 2009; 36(3): 155-160

21. Lawn JE, Kambafwile JM, Horta BL, Barros FC, Cousens S. 'Kangaroo Mother Care' to Prevent Neonatal Deaths due to Preterm Birth Complications. Int J Epidemiol, 2010;39:144-154

22. Ruiz-Peláez JG, Charpak N, Cuervo LG. Kangaroo Mother Care, an Example to Follow from Developing Countries. BMJ 2004;329:1179-82

23. Bergman NJ, Linley LL, Fawcus SR. Randomized Controlled Trial of Skin-To-Skin Contact from Birth Versus Conventional Incubator for Physiological Stabilization In 1200- to 2199-Gram Newborns. Acta Paediatr 2004;93:779-785

24. Quasem MI, Sloan NL, ChowdhuryA, Ahmed S, Winikoff B, Chowdhury AMR. Adaptation of Kangaroo Mother Care for CommunityBased Application. J Perinatology, 2003; 23: 646-51

25. Catteneo A, Davanzo R, Worku B et al. Kangaroo Mother Care Low Birth Infants; A Randomized Controlled Trail in Different Setting. Acta Pediatr 1998;87:976-8526

26. Rekha F, Browne N. Lessons Learnt from Introducing Kangaroo Care in a Rural Hospital in Bangladesh. 10th ASCON Abstract no.94

27. Pervin J, Moran A, Yeasmin S, Khan AF, Rahman A, Rahman M, et al. Kangaroo Mother Care in a Rural Hospital in Matlab, Bangladesh: Some Preliminary Findings. 12th ASCON 2009 Abstract S094 (161)

28. Bergh AM, Pattinson RC. Development of a Conceptual Tool for the Implementation of Kangaroo Mother Care. Acta Paediatr. 2003;92: 709-714 29. Sloan NL, Ahmed S, Maqsudul I, Mitra SN. Experiences with Community Kangaroo Mother Care in Very Low-Income Settings. Current Women's Health Reviews 2011;7(3): 310-315

30. Nasreen H, Ahmed S M, Begum HA, Afsana K. Maternal, Neonatal and Child Health Programmes in Bangladesh, Review of good practices and lessons learned, 2007, (Reprint 2010), Research Monograph Series No. 32 